\title{
Differences between the antibiotic prescribing pattern of newly arrived refugees in Germany and the German population
}

\author{
Fabian Kahl ${ }^{1^{*}}$ (D) and Thomas Kühlein ${ }^{2}$
}

\begin{abstract}
The number of refugees arriving in Europe increased dramatically in 2015, challenging the German health system. Amongst others, the treatment of infectious diseases is an important topic in refugee healthcare. A high prevalence of multi-drug-resistant organisms has been identified among the refugee population. Still, little is known about the prescription of antibiotic medication for refugees. We conducted a descriptive analysis of all antibiotics prescribed to newly arrived refugees who were treated as outpatients between 10/01/2014 and 09/30/2015 in Erlangen, an average sized German town. The City's invoicing documents were used to collect data on prescriptions written for refugees. Basic penicillins, aminopenicillins with beta-lactamase inhibitor and cephalosporins constituted the largest proportion of antibiotics prescribed in the adult refugee group. Of these, both aminopenicillins with betalactamase-inhibitor as well as basic penicillins were prescribed significantly more often compared to non-refugees. We conclude that the high percentage of prescriptions of aminopenicillins with beta-lactamase inhibitor is striking and should be further investigated.
\end{abstract}

\section{Correspondence}

Since the beginning of the refugee crisis in 2015, medical care for refugees has posed a challenge to European healthcare systems, including the German health system. Amongst many other health problems these patients present with, infectious diseases are salient [1,2], including a high prevalence of multidrug-resistant organisms (MDRO) like methicillin-resistant Staphylococcus aureus (MRSA) [3-6]. Little is known about the medical treatment of infectious diseases of refugees in Germany [7], but the studies mentioned above call for a better surveillance of prescribed antibiotics, as they can be both a cause and a consequence of a high MDRO prevalence. Therefore, we present here the pattern of antibiotics prescribed to newly arrived refugees in the city of Erlangen, assessed through a retrospective analysis of all outpatient prescriptions for newly arrived refugees in Erlangen over

\footnotetext{
* Correspondence: fabian.kahl@fau.de

'Institut für Geschichte und Ethik der Medizin, Friedrich-Alexander Universität

Erlangen-Nürnberg, Glückstraße 10, 91054 Erlangen, Germany

Full list of author information is available at the end of the article
}

the period from 10/01/2014-09/30/2015. The data basis we used were anonymised invoicing documents of the City's Department of Social Services.

For a better comparison with literature reporting on antibiotic prescriptions in Germany, we calculated the defined daily dose (DDD) [8] of each antibiotic prescribed and classified the substances in classes according to the classification of Augustin et al. [9], as also used by Batzing-Feigenbaum et al. [10]. Table 1 shows all antibiotic substances prescribed in this study as classes.

We analysed the antibiotic prescribing pattern of two groups which, due to their size, allowed a meaningful analysis: Persons from 0 to 14 years, in the following referred to as "children group", and persons from 20 to 39 years, in the following referred to as "adult group".

While we did not find major differences in the children group (0-14 years) compared to children insured by the German statutory health insurance (gesetzliche Krankenversicherung, GKV), as our results (see Table 2) are equal to the analyses of GKV-insured children by Augustin et al. [9] and Bätzing-Feigenbaum et al. [10], 
Table 1 Overview and Classification of all prescribed antibiotics

\begin{tabular}{|c|c|c|}
\hline Antibiotic group & ATC-classes & Substance \\
\hline \multirow[t]{2}{*}{$\begin{array}{l}\text { Aminopenicillins with } \\
\text { beta-lactamase inhibitor (BLI) }\end{array}$} & J01CR02 & $\begin{array}{l}\text { amoxicillin and enzyme } \\
\text { inhibitor }\end{array}$ \\
\hline & J01CR04 & sultamicillin \\
\hline \multirow[t]{3}{*}{ Basic penicillins } & J01CA04 & amoxicillin \\
\hline & J01CE02 & phenoxymethylpenicillin \\
\hline & J01CE10 & $\begin{array}{l}\text { benzathine } \\
\text { phenoxymethylpenicillin }\end{array}$ \\
\hline \multirow[t]{5}{*}{ Cephalosporins } & J01DC02 & cefuroxime \\
\hline & J01DC04 & cefaclor \\
\hline & J01DD08 & cefixime \\
\hline & J01DD13 & cefpodoxime \\
\hline & J01DD14 & ceftibuten \\
\hline \multirow[t]{3}{*}{ Fluoroquinolones } & J01MA01 & ofloxacin \\
\hline & J01MA02 & ciprofloxacin \\
\hline & J01MA12 & levofloxacin \\
\hline \multirow[t]{5}{*}{ Macrolides/lincosamides } & J01FA01 & erythromycin \\
\hline & J01FA06 & roxithromycin \\
\hline & J01FA09 & clarithromycin \\
\hline & J01FA10 & azithromycin \\
\hline & J01FF01 & clindamycin \\
\hline \multirow{2}{*}{$\begin{array}{l}\text { Nitrofurantoin/fosfomycin/ } \\
\text { nitroxolin }\end{array}$} & J01XE01 & nitrofurantoin \\
\hline & J01XX01 & fosfomycin \\
\hline Sulfonamide/trimethoprim & J01EE01 & $\begin{array}{l}\text { sulfamethoxazole and } \\
\text { trimethoprim }\end{array}$ \\
\hline Tetracyclines & J01AA02 & doxycycline \\
\hline
\end{tabular}

we found striking deviations in the adult group: Here, of 478 drugs prescribed in total, 100 were antibiotics. Antibiotics therefore accounted for $20.9 \%$ of all prescriptions in this group. The most frequently prescribed class of antibiotics was basic penicillins (31\%), followed by aminopenicillins with beta-lactamase inhibitors (BLI) (21\%) and cephalosporins (16\%).

To adults, overall 1059.5 DDD of antibiotics were prescribed. Basic penicillins constituted the greatest part with $44 \%$, followed by aminopenicillins with BLI (21\%), cephalosporins (13\%) and macrolides (10\%) (see Table 2).

In comparison to GKV-insured patients, refugees received broad spectrum antibiotics and aminopenicillins with BLI more often. Bätzing-Feigenbaum et al. [10] found a percentage of $25.9 \%$ for basic penicillins of all prescribed antibiotic DDD, while aminopenicillins with BLI had a rate of $2.9 \%$ in the age group 15-69 years [10]. Another striking difference is found for the prescriptions of tetracyclines, where we found a percentage of $3.8 \%$ at all prescribed DDD in the adult group, while for the GKV-insured persons, Bätzing-Feigenbaum et al. observed a percentage of $17.7 \%$ for tetracyclines [10]. Unfortunately, when analysing the prescriptions, it was not possible to infer anything about the diagnosis leading to the prescriptions. Therefore, a specific analysis as to the cause of the strikingly high percentage of aminopenicillins with BLI in the adult group could not be carried out. One could assume that the illnesses treated in the refugee group were dissimilar to the GKV-insured. However, this seems not to be the case. Alberer et al. [2] and Jung [1] described the distribution of diagnoses in refugee patients. Beside symptom diagnoses, respiratory tract infections were the most common. It is well known that these diagnoses are typical for almost any GP's office, so the spectrum of diseases seems unlikely to account for the deviant antibiotic prescription.

Unfortunately, we can only report on a small number of antibiotic prescriptions. It was also not possible to gain information about the diagnoses leading to the prescriptions. However, we offer the first insight into the antibiotic prescription pattern of refugees in Germany.

Table 2 Prescriptions of antibiotic classes in the adult and children group

\begin{tabular}{|c|c|c|c|c|}
\hline \multirow{2}{*}{$\begin{array}{l}\text { Prescriptions in DDD } \\
\text { Antibiotic groups }\end{array}$} & \multicolumn{2}{|c|}{ adults (20-39 years) } & \multicolumn{2}{|c|}{ children ( $0-14$ years) } \\
\hline & DDD absolute & DDD relative & DDD absolute & DDD relative \\
\hline Aminopenicillins with beta-lactamase inhibitor & 218,5 & $20,62 \%$ & 10,50 & $2,61 \%$ \\
\hline Basic penicillins & 466,5 & $44,03 \%$ & 200,50 & $49,81 \%$ \\
\hline Cephalosporins & 141,5 & $13,36 \%$ & 110,50 & $27,45 \%$ \\
\hline Fluoroquinolones & 21 & $1,98 \%$ & 0 & $0,00 \%$ \\
\hline Macrolides/lincosamides & 109 & $10,29 \%$ & 55,00 & $13,66 \%$ \\
\hline Metronidazol & 0 & $0,00 \%$ & 0 & $0,00 \%$ \\
\hline Nitrofurantoin/fosfomycin/nitroxolin & 28 & $2,64 \%$ & 1,00 & $0,25 \%$ \\
\hline Sulfonamide/trimethoprim & 35 & $3,30 \%$ & 5,00 & $1,24 \%$ \\
\hline Tetracyclines & 40 & $3,78 \%$ & 20,00 & $4,97 \%$ \\
\hline Others & 0 & $0,00 \%$ & 0 & $0,00 \%$ \\
\hline Total & 1059,5 & $100,00 \%$ & 402,50 & $100,00 \%$ \\
\hline
\end{tabular}




\section{Conclusion}

Due to the fact, that the prevalence for MRSA in refugees is not only higher compared to the German population [4], but exceeds the prevalence of MRSA in other known risk groups [5], the high prescription rate of aminopenicillins with BLI in the adult group might be reason for alarm. Considering the limitations of the study, we see that data regarding refugee health is lacking and a better surveillance of prescription rates is required.

\section{Acknowledgements}

The present work was performed in fulfillment of the requirements for obtaining the degree "Dr. med." at the Friedrich-Alexander-Universität Erlangen-Nürnberg (FAU).

We acknowledge support by Deutsche Forschungsgemeinschaft and Friedrich-Alexander-Universität Erlangen-Nürnberg (FAU) within the funding programme Open Access Publishing.

\section{Funding}

No funding was received for this project.

\section{Availability of data and materials}

The data that support the findings of this study are available from the City of Erlangen (Amt für Soziales, Arbeit und Wohnen) but restrictions apply to the availability of these data, which were used under license for the current study, and so are not publicly available. Data are however available from the authors upon reasonable request and with permission of the City of Erlangen (Amt für Soziales, Arbeit und Wohnen).

\section{Authors' contributions}

FK analysed and interpreted the data, TK supervised the study and contributed to the writing of the manuscript. Both authors read and approved the final manuscript.

\section{Ethics approval and consent to participate}

Due to the study's nature, which is a retrospective analysis of anonymised data without contact to patients, an ethic approval was not required according to German law. As the study only used routinely-collected, anonymized data, the issue of informed patients' consent does not apply.

\section{Consent for publication}

Not applicable.

\section{Competing interests}

The authors report no conflict of interest.

\section{Publisher's Note}

Springer Nature remains neutral with regard to jurisdictional claims in published maps and institutional affiliations.

\section{Author details}

${ }^{1}$ Institut für Geschichte und Ethik der Medizin, Friedrich-Alexander Universität Erlangen-Nürnberg, Glückstraße 10, 91054 Erlangen, Germany.

${ }^{2}$ Allgemeinmedizinisches Institut, Friedrich-Alexander Universität

Erlangen-Nürnberg, Universitätsstraße 29, 91054 Erlangen, Germany.

Received: 16 July 2017 Accepted: 12 January 2018

Published online: 29 January 2018

\section{References}

1. Jung F. Das Bremer Modell. 2011. http://www.gesundheitsamt.bremen.de/ sixcms/media.php/13/3_GBE_Gesundheitsversorgung_Asylsuchender.pdf. Accessed 15 Jan 2018.

2. Alberer M, Wendeborn M, Löscher T, Seilmaier M. Erkrankungen be Flüchtlingen und Asylbewerbern. Dtsch Med Wochenschr. 2016;141:e8-e15.

3. Tenenbaum T, Becker K-P, Lange B, Martin A, Schafer P, Weichert S, Schroten $\mathrm{H}$. Prevalence of multidrug-resistant organisms in hospitalized pediatric refugees in an university Children's Hospital in Germany 20152016. Infect Control Hosp Epidemiol. 2016;37:1310-4.

4. Reinheimer C, Kempf VAJ, Jozsa K, Wichelhaus TA, Hogardt M, O'Rourke F, Brandt C. Prevalence of multidrug-resistant organisms in refugee patients, medical tourists and domestic patients admitted to a German university hospital. BMC Infect Dis. 2017;17(17).

5. Heudorf U, Albert-Braun S, Hunfeld K-P, Birne F-U, Schulze J, Strobel K, et al. Multidrug-resistant organisms in refugees: prevalences and impact on infection control in hospitals. GMS Hyg Infect Control. 2016;11:Doc16.

6. Reinheimer C, Kempf VAJ, Gottig S, Hogardt M, Wichelhaus TA, O'Rourke F, Brandt C. Multidrug-resistant organisms detected in refugee patients admitted to a university hospital, Germany JuneDecember 2015. Euro Surveill. 2016;21.

7. Razum O, Bunte A, Gilsdorf A, Ziese T, Bozorgmehr K. Gesundheitsversorgung von Geflüchteten: Zu gesicherten Daten kommen. Deutsches Ärzteblatt. 2016;113:130-3.

8. Fricke U, Günther J, Zawinell A, Zeidan R. Anatomisch-therapeutischchemische Klassifikation mit Tagesdosen für den deutschen Arzneimittelmarkt: ATC-Index mit DDD-Angaben für den deutschen Arzneimittelmarkt. 14th ed. Berlin; 2015.

9. Augustin J, Mangiapane S, Kern W. Antibiotika-Verordnungsprävalenzen im Jahr 2010. 2012. http://www.versorgungsatlas.de/fileadmin/ziva_docs/ Antibiotika_Bericht_final.pdf. Accessed 15 Jan 2018.

10. Batzing-Feigenbaum J, Schulz M, Schulz M, Hering R, Outpatient Antibiotic KWW. Prescription. Dtsch Arztebl Int. 2016;113:454-9.
Submit your next manuscript to BioMed Central and we will help you at every step:

- We accept pre-submission inquiries

- Our selector tool helps you to find the most relevant journal

- We provide round the clock customer support

- Convenient online submission

- Thorough peer review

- Inclusion in PubMed and all major indexing services

- Maximum visibility for your research

Submit your manuscript at www.biomedcentral.com/submit
C Biomed Central 